BMJ Open Ophthalmology

\title{
Ophthalmic manifestations of proboscis lateralis
}

\author{
Ekta Singh Sahu (D) ," Pavan Humesh Shroff (D) ," Animesh Sahu, ${ }^{2}$ Arun Bhargava, \\ Balkishan Sharma ${ }^{3}$
}

To cite: Sahu ES, Shroff PH, Sahu A, et al. Ophthalmic manifestations of proboscis lateralis. BMJ Open Ophthalmology 2021;6:e000558. doi:10.1136/ bmjophth-2020-000558

- Additional supplemental material is published online only. To view, please visit the journal online (http://dx.doi. org/10.1136/bmjophth-2020000558).

Received 5 July 2020
Accepted 12 April 2021

Received 5 July 2020
Accepted 12 April 2021

Check for updates

(C) Author(s) (or their employer(s)) 2021. Re-use permitted under CC BY-NC. No commercial re-use. See rights and permissions. Published by BMJ.

${ }^{1}$ Department of Vitreo-Retina, Retina Speciality Hospital, Indore, Madhya Pradesh, India ${ }^{2}$ Department of Oculoplasty and Cataract, Retina Speciality Hospital, Indore, Madhya Pradesh, India

${ }^{3}$ Department of Community Medicine (Biostatistics), Sri Aurobindo Medical College \& PG Institute, Indore, Madhya Pradesh, India

Correspondence to Dr Ekta Singh Sahu; drektasinghsahu@gmail.com

\section{ABSTRACT}

Proboscis lateralis $(\mathrm{PL})$ is a rare congenital malformation of the craniofacial structure with varied clinical associations. None of the studies documented a discrete review of ophthalmic presentations in PL. The principal aim of the present study is to explore the ophthalmic manifestations of PL. The ancillary goal is to derive a relationship between congenital deformity in PL and various ophthalmic anomalies. Databases were searched in order to obtain articles related to PL. A qualitative systematic analysis of 100 subjects was performed. In PL, eyelid coloboma $(32.6 \%)$ is the most common ocular feature, followed by hypertelorism (25.3\%), iris coloboma (22.4\%), lacrimal system abnormality (20.7\%), malpositioned eyebrow (14.4\%) and retinochoroidal coloboma (12.9\%). Sinonasal deformity is the most common systemic abnormality, detected in $87.9 \%$ of cases of PL, as compared with central nervous system involvement (56.2\%) and other anomalies. The analysis showed a strong significant association between brain abnormalities and hypertelorism $(p=0.000)$ and between brain abnormalities and microophthalmia/anophthalmia $(p=0.000)$. Statistically significant association was noted between cumulative ocular abnormalities and cumulative systemic abnormalities $(p=0.001)$. The present study on PL reviewed the salient features of this rare congenital disorder. The study outcome provides a new aspect to concomitant ocular abnormalities. This study supports the view that other congenital anomalies in cases of PL had significant influence on certain ophthalmic anomalies.

\section{INTRODUCTION}

Proboscis lateralis (PL) is a rare, congenital, off-centre, vertical deformity characterised by a rudimentary nose-like structure. The documented occurrence is less than 1 per 100000 population. ${ }^{1}$ It is embryologically related to a facial fusion defect. The tubular process often has a unilateral presentation and projects from the inner corner of the orbital roof. ${ }^{2}$ It measures around $2-3 \mathrm{~cm}$ long and $1 \mathrm{~cm}$ in diameter. The structure may include all the tissue lines analogous to a normal nose. Sometimes a patent tract transverses the entire proboscis exuding discharge. ${ }^{3}$

The first case of PL was described in 1861 by Forster, $^{2}$ and many reports have followed afterwards. Of interest to an ophthalmologist are the concomitant ocular anomalies reported at around $44 \%-70 \% .^{1}{ }^{4}$ The spectrum of ocular abnormalities includes hypertelorism, anophthalmia, microphthalmia, abnormal lacrimal system, microcornea, lenticular opacities, coloboma eyelid, coloboma iris and retinochoroidal coloboma. Less common are cyclopean eye, hypoplastic orbit, ptosis, corneal opacity, etc. ${ }^{5}$ The literature on this ophthalmic condition is sparse given its rare occurrence. There are only four cases published in ophthalmic journals: two were published in the Archives of Ophthalmology ${ }^{26}$ in 1947 and 2001 and the other two in Ophthalmic Plastic $\mathcal{E}$ Reconstructive Surgery ${ }^{7}$ in 2008 and 2016. The primary aim of this review was to study this rare malformation from an ophthalmic perspective, and second to derive a correlation between ocular and associated systemic malformations.

\section{METHODS AND MATERIALS}

Patient and public involvement

Patients were not involved directly or indirectly from inception of research to the final documentation for readability or accuracy.

\section{Study sources and selection}

We identified publications pertaining to PL and reviewed cases of PL with a retrospective chart. Investigators collected cases recorded between January 1885 and November 2019. Cases were evaluated and the data were compiled.

An electronic-based systematic literature search was performed in PubMed, PubMed Central, Cochrane Library, ResearchGate and Google Scholar. Search keywords included 'proboscis lateralis' and/or 'supernumerary nostril'. Filtered database search revealed 153 case reports/case series according to their titles. From the 153 publications, we identified a total of 97 articles with full-text manuscripts. Full text was assessed for eligibility independently by two authors. The reference lists of published 


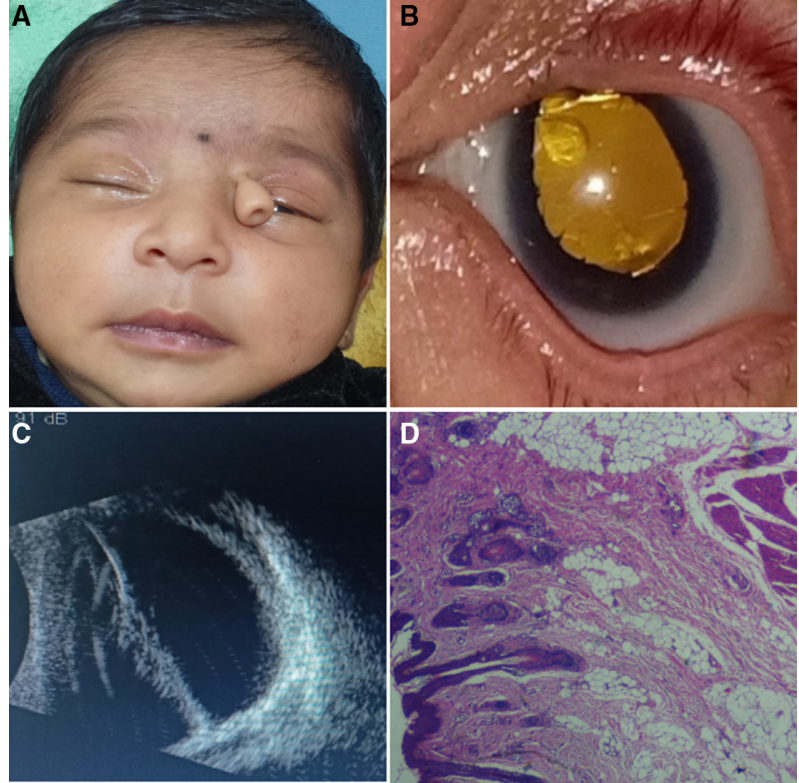

Figure 1 (A) Full face of an infant showing left-sided proboscis lateralis and normal nose. (B) Anterior segment photo showing abnormally shaped cornea, corectopia, persistent pupillary strands, large Mittendorf dot, lenticular opacity and yellow fundal glow. (C) B scan ultrasound showing echogenic stalk extending from the back of the lens towards the retinal surface suggestive of persistent hyperplastic primary. (D) Histological section showing the stratified squamous epithelium with adnexal gland overlying the mixture of mature fibrolipomatous tissue, striated muscle fibres and blood vessels (H\&E $\times 10$ magnification).

cases obtained during this phase were also screened. Twelve relevant articles were further identified. Nine cases were later excluded based on the following: (1) non-English articles, (2) reports with stillborn or those who did not survive long enough to undergo an ocular examination, and (3) reports with no mention of ocular examinations or extractable ocular data. We identified 100 cases, including one of our own (figure 1) which met our research criteria for analysis. The search strategy and the Preferred Reporting Items for Systematic Reviews and Meta-Analyses flow chart illustrating the process are presented in figure 2.

\section{Data extraction}

Data were extracted from each case and further processed. We collected the demographic characteristics, ocular findings and systemic manifestations of each patient. The present study focused on ocular anomalies under two subdivisions: adnexa and intraocular manifestations. The adnexa included the orbit, eyebrow, eyelid, conjunctiva and extraocular muscles. The intraocular subset included the rest of the ocular structure. Micro-ophthalmia or anophthalmia evaluation was carried out as a separate entity. Besides the documented adnexa abnormalities, facial photos were scanned to elaborate on the details of the adnexa. The intraocular abnormalities reported were the ones included and accounted. The rest of the intraocular findings were assumed normal if not specified. Information collected on the associated systemic anomalies was categorised into sinonasal abnormality, oroclefting, facial deformity and other systemic malformations.

Further, patients were classified into four groups as per the Boo-Chai's classification ${ }^{4}$ for convenience of comparison with other series. A scoring system is formulated to measure the extent of ocular and systemic abnormalities for each subjects. A score of 1 is allocated to each abnormal ocular and systemic finding. These points are then summated to provide a total scores which draws up the distinctive cumulative ocular and cumulative systemic score reflecting extent of abnormalities for each subject. The higher the cummulative score the more abnormalities. The scores aid in deriving association between ocular and systemic abnormalies as well as comparison among various study attributes. The cumulative ocular score was further allocated into complete adnexa score and complete intraocular score for subanalysis.

\section{Statistical analysis}

Data were analysed by SPSS V.7.0 software using descriptive and inferential statistics. Results for continuous variables were presented as mean \pm SD. Categorical results were presented in numbers (\%). We assumed that the observations recorded for a continuous variable had followed a normal distribution. Pearson's $\chi^{2} /$ Fisher's exact tests were used to investigate the association between the selected variables. A probability value of $p=0.05$ was considered statistically significant, while values of $\mathrm{p}=0.01$ and above were considered strongly significant.

\section{RESULTS}

Given the retrospective nature of the present study, the computed results have excluded missing variables. Gender was reported for 88 patients, 53 of whom were

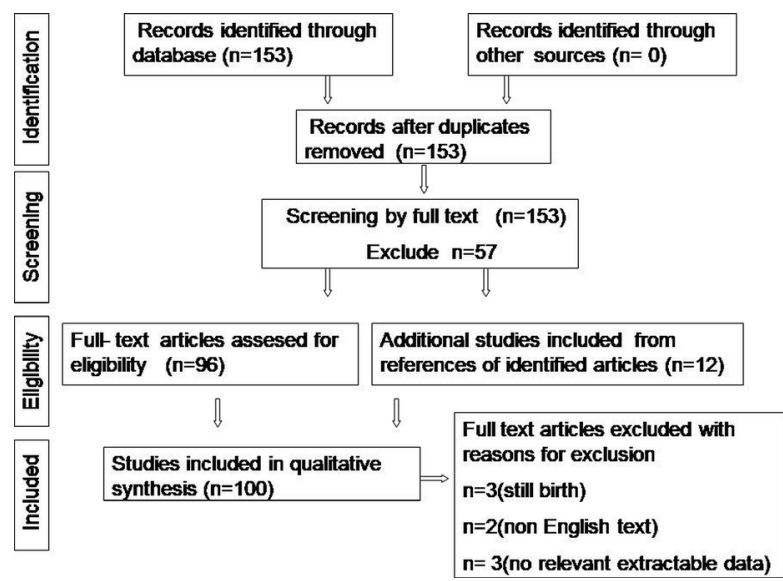

Figure 2 PRISMA flow chart illustrating the process of selection of case records for systematic review. PRISMA, Preferred Reporting Items for Systematic Reviews and MetaAnalyses. 


\begin{tabular}{|c|c|c|c|}
\hline \multirow{2}{*}{$\begin{array}{l}\text { Ocular characteristics of } \\
\text { proboscis lateralis }\end{array}$} & \multicolumn{3}{|c|}{ Eyes, $n(n=100)$} \\
\hline & Observed & Out of* & Percentage \\
\hline Lid coloboma & 31 & 95 & 32.6 \\
\hline Hypertelorism & 21 & 83 & 25.3 \\
\hline Iris coloboma & 17 & 76 & 22.4 \\
\hline $\begin{array}{l}\text { Lacrimal system } \\
\text { abnormality }\end{array}$ & 17 & 82 & 20.7 \\
\hline $\begin{array}{l}\text { Malpositioned/abnormal } \\
\text { eyebrow }\end{array}$ & 12 & 83 & 14.4 \\
\hline $\begin{array}{l}\text { Retinochoroidal } \\
\text { coloboma }\end{array}$ & 8 & 62 & 12.9 \\
\hline Abnormal cornea/opacity & 7 & 75 & 9.33 \\
\hline Orbital wall defect & 6 & 83 & 7.22 \\
\hline Squint & 4 & 83 & 4.81 \\
\hline Proptosis & 3 & 83 & 3.61 \\
\hline Disc coloboma & 2 & 62 & 3.22 \\
\hline Ptosis & 3 & 95 & 3.15 \\
\hline Epicanthus & 3 & 95 & 3.15 \\
\hline Lens opacity & 2 & 73 & 2.73 \\
\hline Hypoplastic orbit & 2 & 83 & 2.40 \\
\hline Orbital mass & 2 & 83 & 2.40 \\
\hline Fissure asymmetry & 2 & 95 & 2.10 \\
\hline
\end{tabular}

${ }^{*}$ The rest of the cases are not observed in the analysed review of literature.

male. The male to female ratio was 1.5 , against $2: 1$ reported in the literature. ${ }^{4}$ The average age at clinical review was $2.45 \pm 4.85$ years, ranging between 0.0 (at birth) and 34.0 years. In 81 cases PL was positioned unilaterally, in 3 cases midline, and 6 reported cases of proboscis-like nares that did not follow any laterality. Literature reports bilateral $\mathrm{PL}^{9}$; however, these cases did not meet the inclusion criteria for the present study and hence excluded. Out of 100 cases, 9 had an atypical position on the cheek, ${ }^{10}$ chin, ${ }^{11}$ ala of the nose,${ }^{12}$ upper lid $^{12}$ and lateral canthus. ${ }^{13}$ Of 41 cases, discharge from PL was present in 26 cases $(63 \%)$.

\section{Ophthalmic structural abnormalities}

The three most common ocular abnormalities in PL were eyelid coloboma (32.6\%), hypertelorism (25.3\%) and iris coloboma $(22.4 \%)$.

Among all eyelid colobomas, lower eyelid involvement was recorded in $21(67.7 \%)$ cases, upper eyelid in $8(25.8 \%)$ cases, and both the upper and lower eyelids were involved in $2(6.45 \%)$ cases. Other observed eyelid abnormalities were fissure asymmetry in five eyes, ptosis in three eyes and epicanthus in two eyes.

Other ophthalmic anomalies included were lacrimal system abnormality (20.7\%), malpositioned/abnormal eyebrow (14.4\%) and retinochoroidal coloboma $(12.9 \%)$. Micro-ophthalmia/anophthalmia was observed in 20 cases $(20 \%)$, of which $13(65 \%)$ were unilateral and $7(35 \%)$ were bilateral. Table 1 presents a summary of the remaining less prevalent ocular abnormalities.
Recorded rare presentations with each case were dystopia, lagophthalmia, malposition of the orbit, nystagmus, conjunctival cyst, abnormally shaped microcornea, corectopia, persistent iris strand, persistent hyperplastic primary vitreous, peripapillary staphyloma, optic disc pit, telecanthus, choroidal cleft and retinal detachment.

\section{Systemic associated abnormalities}

The most common systemic abnormality associated with PL was sinonasal deformity with $87.9 \%$ (87 of 99), followed by central nervous system involvement with $56.2 \%$ (18 of 32), facial deformity with $54.7 \%$ (29 of 53 ) and cleft lip/palate with $24.0 \%$ (24 of 100). Table 2 shows the systemic abnormalities with predominance of their subtypes. The frequently observed subtypes comprised heminasal aplasia $(53.5 \%)$ and ethmoidal hypoplasia (22.2\%) among cases of sinonasal deformity, high-arched palate $(15.1 \%)$ among facial deformities, and ventricular dilatation (34.4\%) among brain abnormalities. Out of 32 cases, the less common systemic association included genital hypoplasia, which was found in two cases, and one case each of kidney agenesis, single ureter, ventricular septal defect and patent ductus arteriosus. Infrequently detected anomalies included inguinal hernia, single umbilical cord, absent premaxilla and abnormal pyriform.

The results of the analysis of the classified groups are as follows: group 1 of PL with a normal nose was the least prevalent (11.2\%); group 2 was associated with only nose deformity, with a prevalence of $18.4 \%$; group 3 involving the nose and the eyes and/or adnexa abnormalities was the most common (46.9\%); and nasal and ocular defects along with cleft lip and/or palate comprise group $4(23.5 \%)$. These results support the observation made in Khoo and Boo-Chai's study, ${ }^{4}$ where group 3 was the most common and group 1 was the rarest.

Associations between ophthalmic and systemic abnormalities The statistical agreement showed the significant association between cumulative ocular abnormalities and cumulative systemic abnormalities $(p=0.001)$. Yet an association between cumulative ocular abnormalities and brain abnormalities was insignificant $(\mathrm{p}=0.249)$. Further analysis establishes a significant relationship between brain abnormalities and complete adnexa findings $(p=0.018)$. No statistical association was found between complete intraocular findings and brain abnormalities $(\mathrm{p}=0.991)$. Hypertelorism and micro-ophthalmia/anophthalmia showed a significant association with brain abnormalities (both $\mathrm{p}=0.000$ ) (table 3).

Online supplemental table 1 provides a comprehensive chart of ocular and systemic findings in 100 patients.

\section{DISCUSSION}

Ophthalmic manifestations in PL have unsatisfactory documentation in the past, either in small series or case 
Table 2 Assessment of systemic abnormalities of proboscis lateralis

\begin{tabular}{|c|c|c|c|c|c|}
\hline \multirow[b]{2}{*}{ Systemic abnormality } & \multicolumn{3}{|c|}{ Eyes $(n=100)$} & \multirow[b]{2}{*}{ Subtype of systemic abnormality } & \multirow[b]{2}{*}{ n (\%) } \\
\hline & $\mathbf{n}$ & Out of ${ }^{\star}$ & $\%$ & & \\
\hline \multirow[t]{4}{*}{ Sinonasal deformity } & 87 & 99 & 87.9 & Heminasal aplasia & $53(53.5)$ \\
\hline & & & & Heminasal hypoplasia & $21(21.2)$ \\
\hline & & & & Ethmoidal hypoplasia/aplasia & $22(22.2)$ \\
\hline & & & & Maxillary hypoplasia/aplasia & $21(21.2)$ \\
\hline \multirow[t]{3}{*}{ Facial deformity } & 29 & 53 & 54.7 & High-arched palate & $8(15.1)$ \\
\hline & & & & Wide forehead & $6(11.3)$ \\
\hline & & & & Elongated philtrum & $4(7.6)$ \\
\hline Cleft lip/palate & 24 & 100 & 24.0 & & \\
\hline \multirow{4}{*}{$\begin{array}{l}\text { Central nervous system } \\
\text { involvement }\end{array}$} & 18 & 32 & 56.2 & Ventricular dilatation & $11(34.4)$ \\
\hline & & & & Macrocephaly & $9(28.1)$ \\
\hline & & & & Corpus callosum anomalies & $5(15.6)$ \\
\hline & & & & Optic nerve hypoplasia & $5(15.6)$ \\
\hline Abnormal genitals & 2 & 32 & 6.3 & Genital hypoplasia & $2(6.3)$ \\
\hline Abnormal kidney & 1 & 32 & 3.1 & $\begin{array}{l}\text { Kidney agenesis, duplex renal pelvis with single } \\
\text { ureter }\end{array}$ & $1(3.1)$ \\
\hline $\begin{array}{l}\text { Cardiovascular system } \\
\text { involvement }\end{array}$ & 1 & 32 & 3.1 & $\begin{array}{l}\text { Ventricular septal defect, patent ductus } \\
\text { arteriosus }\end{array}$ & $1(3.1)$ \\
\hline
\end{tabular}

${ }^{*}$ The rest of the cases are not observed in the analysed review of literature.

reports. However, combined data offer an approximate prevalence of ocular abnormalities.

A summary of embryonic development is necessary to understand the genesis and pattern of systemic malformations and its relationship with ocular abnormalities. Head and face development occurs between 4 and 8 weeks of embryogenesis. The insult during this period results in a constellation of malformations. However, the causative factor is uncertain. ${ }^{14}$

The development in early embryo occurs via series of orderly induction. Embryonic induction is a process by which a group of cells called 'organiser' influence and differentiate the adjacent embryonic cells. This is a recurring phenomenon and an array of organisers are produced in an orderly progression, from a "primary organiser' to secondary and tertiary organisers, and so on. 'Each order of organisation results in a particular development abnormality'. The interaction between the inducer and the tissue being induced is probably chemically mediated. The extent of interaction is limited by finite distance and critical exposure time within a field volume. The influence of organiser is mostly found at the centre of the field volume and least at its periphery. An overlap from the surrounding organisers at the field perimeters may result in small or otherwise malformed structure.

The notochordal process is the first and the most important organiser in the head of the embryo. It induces formation of neural tube and foregut, which act as secondary organisers. The neural tube is closed by 4 weeks of gestation and a primitive forebrain (prosencephalon) emerges at its rostral end. Neural crest-derived mesenchyme from the prosencephalic region forms the unpaired central frontonasal process. During weeks 5 and 6 of gestation, a series of cleavages in the prosencephalon induce the neuroepithelium placodes in pairs (optic, otic, olfactory in the same order). Similarly, the foregut organises the formation of the maxillary process from the first branchial arch. The primary defect of ventral induction during prosencephalon development results in the most profound anomalies, holoprosencephaly. In holoprosencephaly, various states of failure of differentiation occur, including improper placement of the interplacode area. As a result, the central proboscis and other severe anomalies such as cyclopia, midfacial clefts and severe hypotelorism develop. ${ }^{15}$

The olfactory placode is the primary organiser of a developing nose. At week 5 of gestation, the nasal groove is formed from the olfactory placode. It interacts with a frontonasal process to define the maxillary process, the medial nasal process and the lateral nasal process. During weeks $6-7$, the maxillary process induces transformation of the nasal and oral cavity. The medial nasal prominences merge with each other across the midline and interact with growing maxillary processes to form the intermaxillary segment. The ventral end of the median nasal process extends into the mesenchyme of the roof of the mouth. This enlarged area is identified as globular process. The interaction between maxillary process, lateral nasal process and the intermaxillary segment ultimately forms the upper lip, the zygomas, the maxilla bilaterally, the philtrum and the nasal bridge by week 10 . The primitive anterior nares, mouth and alveolus form when the maxillary process meets the globular process. 
Table 3 Associations between brain abnormality with adnexa hypertelorism and micro-ophthalmia/anophthalmia

\begin{tabular}{|c|c|c|c|c|c|c|}
\hline Brain abnormality & Total, n (\%) & \multicolumn{3}{|c|}{ Adnexa hypertelorism, n (\%) } & \multicolumn{2}{|c|}{$\begin{array}{l}\text { Micro-ophthalmia/anophthalmia, } \\
\mathrm{n}(\%)\end{array}$} \\
\hline Not applicable (NA) & $71(71.0)$ & $14(14.0)$ & $52(52.0)$ & $5(5.0)$ & $64(64.0)$ & $7(7.0)$ \\
\hline Normal & $12(12.0)$ & $2(2.0)$ & $8(8.0)$ & $2(2.0)$ & $10(10.0)$ & $2(2.0)$ \\
\hline Ventricular dilatation & $2(2.0)$ & $0(0.0)$ & $0(0.0)$ & $2(2.0)$ & $0(0.0)$ & $2(2.0)$ \\
\hline Cystic lesion & $2(2.0)$ & $1(1.0)$ & $0(0.0)$ & $1(1.0)$ & $1(1.0)$ & $1(1.0)$ \\
\hline Ventricule dilatation, encephalocoele & $1(1.0)$ & $0(0.0)$ & $0(0.0)$ & $1(1.0)$ & $0(0.0)$ & $1(1.0)$ \\
\hline $\begin{array}{l}\text { Optic nerve hypoplasia/absent, } \\
\text { ventricule dilatation }\end{array}$ & $1(1.0)$ & $0(0.0)$ & $0(0.0)$ & $1(1.0)$ & $1(1.0)$ & $0(0.0)$ \\
\hline $\begin{array}{l}\text { Ventricule dilatation, corpus callosum } \\
\text { anomalies, encephalocoele, others }\end{array}$ & $1(1.0)$ & $0(0.0)$ & $0(0.0)$ & $1(1.0)$ & $1(1.0)$ & $0(0.0)$ \\
\hline $\begin{array}{l}\text { Ventricule dilatation, corpus callosum } \\
\text { anomalies, cystic lesion }\end{array}$ & $1(1.0)$ & $0(0.0)$ & $0(0.0)$ & $1(1.0)$ & $0(0.0)$ & $1(1.0)$ \\
\hline $\begin{array}{l}\text { Arachnoid cyst in the fossa, brain } \\
\text { asymmetry }\end{array}$ & $1(1.0)$ & $0(0.0)$ & $1(1.0)$ & $0(0.0)$ & $1(1.0)$ & $0(0.0)$ \\
\hline Others & $3(3.0)$ & $2(2.0)$ & $1(1.0)$ & $0(0.0)$ & $2(2.0)$ & $1(1.0)$ \\
\hline Total & $100(100.0)$ & 19 (19.0) & $62(62.0)$ & 19 (19.0) & $80(80.0)$ & $20(20.0)$ \\
\hline$P$ value (LOS) & & $\chi_{24}^{2}=\epsilon$ & $(p=0.000)$ & & $\chi_{12}^{2}$ & ${ }^{36} \dagger^{\prime}(p=0.000)$ \\
\hline
\end{tabular}

*35 cells $(89.7 \%)$ have expected count less than 5 . The minimum expected count is .19 .

†2 3 cells $(88.5 \%)$ have expected count less than 5 . The minimum expected count is 20 .

For all obvious reasons, the maxillary process is key to the development of facial structures. The maxillary process regulates and gets regulated by the optic, otic and olfactory centres. ${ }^{15}$ Hence, any localised facial defect may harbour maxillary maldevelopment and vice versa.

During expansion of the medial nasal prominence, a fissure may develop, leading to two abnormal fragments of the prominence. The abnormal lateral fragment merges with the lateral nasal prominence and forms PL. The medial fragment, which merges with the unaffected side, is destined to another fate. This deviation results in a PL with abnormal nose and an additional hypoplastic maxillary prominence can have various associated abnormalities. Alternatively, an extra nasal placode when arranged in a vertically stacked manner on the affected side forms a PL with a normal nose. The lower placode contributes to formation of a normal nose, while the upper placode remains isolated and develops into a PL. 1416

Development of eye and palate gets affected when the inductive influence on their adjacent fields deviates. Eye development begins with optic placode formation from the neuroectoderm at week 3 of embryogenesis. Around week 5, auto-invagination in the optic vesicles creates a double-walled neuroectodermal optic cup. At the same time the optic vesicles interact with the surface ectoderm to form lens placode, which transforms into future lens. The connections of optic vesicle to the forebrain attenuate to form optic stalks with a groove on their inferior surfaces. This groove is referred to as optic or choroidal fissure and closes by week 8 . Inadequate closure of the optic furrow results in coloboma of the iris, retina and disc. ${ }^{14}$ The interplay between the maxillary process and other developing mass shapes the extraocular structure. At week 7 , the maxillary process and the lateral nasal process interact to form the lacrimal apparatus. The nasolacrimal duct forms when plugged epithelium recanalise at week 24 . The mesenchyme along the optic vesicle and maxillary process contributes to the formation of medial aspect of the lower eyelid.

The line of interaction between various processes creates grooves which eventually obliterate between weeks 7 and $20 .^{15}$ Failed fusion between the maxillary process and the undifferentiated facial prominence leads to various degrees of embryonic fissure defect, facial dysmorphogenesis, midfacial hypoplasia, orofacial clefts, intercanthal defect, sinuses hypoplasia and many more. The underdevelopment of the maxillary process 
also affects the medial migration of the eyes from $160^{\circ}$ to a final position of $72^{\circ}$ between the optic axes. ${ }^{14}$ The retarded maxillary growth produces some degree of hypertelorism.

Our finding of $73 \%$ prevalence of ocular abnormalities in PL is consistent with that reported by Khoo and BooChai $(70.5 \%) .{ }^{4}$ On the contrary, English ${ }^{17}$ noted a lower prevalence $(44.0 \%)$ of ocular abnormalities.

Eyelid coloboma represents the most common ocular abnormality in this study. The present study showed higher involvement of the lower eyelid $(67.7 \%)$. Our result is at odds with studies ${ }^{18}$ concluding more of upper eyelid involvement (93\%) in congenital eyelid colobomas. These studies included both isolated colobomas and colobomas coexistent with other craniofacial anomalies. The latter has its origin earlier in the embryogenesis. Craniosynostosis syndrome and cleft disorders contributing to lower eyelid colobomas were under-represented. This introduces a probable source of discrepancy with the present results.

The incidence of ocular coloboma reported in ophthalmic literature is $36 \%$ for the anterior segment, $39 \%$ for the posterior segment and $24 \%$ for both the anterior and posterior segments. ${ }^{19}$ The frequency of iris coloboma $(22.4 \%)$ and retinochoroidal coloboma $(12.9 \%)$ in our study is much lower. Expertise bias while assessing for ocular anomalies at a younger age in the present cohort may explain the difference.

Hypertelorism documented in the current study is lower than that reported by Sakamoto et $a l^{20}(25.3 \%$ vs $54 \%$ ). Illusory hypertelorism without radiographic or CT confirmation is difficult to rule out. Thus, hypertelorism adopted in present study was the one reported by respective authors of case reports or case series included in our study. We did not perform any extra assessment on the specialised image programming as done by Sakamoto et $a l^{20}$ They devised a specialised image programming to exclusively study hypertelorism. This discripency in photographic adaptation of hypertelorism from literature has likely resulted in under-represention of a subset of hypertelorism in our case series. Hence direct comparison between both studies is inappropriate. Sakamoto $e t$ $a l^{20}$ reported cases of hypotelorism, of which nine had cyclopia. All were stillborn or died at an early age with severe holoprosencephaly. It is also worth mentioning the case of a neonate who survived with cyclopia with associated panophthalmitis. ${ }^{6}$

In our cohort, $35 \%$ (7 cases) of micro-ophthalmia/ anophthalmia had bilateral involvement'. Ophthalmic abnormalities are not restricted to the same side of PL as the other side can also be affected. Biber ${ }^{21}$ in his review on PL quoted a case - featuring contralateral malformations. Guion-Almeida $e t a t^{22}$ in a series of cerebro-ocular nares syndrome (CONS) defined a proboscis-like nare. Case number 9 in their series had ocular manifestations on another side of the proboscis-like nares. These observations highlight the possibility of contralateral involvement of ocular malformations as opposed to the popular belief of ipsilateral predilection in PL. The CONS series had higher frequency of brain abnormalities in cases with micro-ophthalmia/anophthalmia and hypertelorism. Including these cases in the present cohort may have influenced and skewed the association results.

In the present study, the associated anomalies in the brain $(56.2 \%)$ and faces $(54.7 \%)$ are higher compared with a study by English ${ }^{17}$ (19\% and 38\%, respectively). The Guion-Almeida et al study ${ }^{22}$ had documented serious brain abnormalities and profound facial oddity. These include a wide forehead, abnormal frontal hairline, high narrow palate and elongated philtrum.

Our study revealed a significant association between brain abnormalities or systemic abnormalities and hypertelorism and micro-ophthalmia/anophthalmia $(p=0.000)$. To our interest, brain or systemic severity did not show an association with cumulative ocular abnormalities $(\mathrm{p}=0.249)$ or intraocular abnormalities ( $\mathrm{p}=0.991$ ). Hence, hypertelorism and micro-ophthalmia) anophthalmia reflect a diagnostic value. Their presence reinforces the need for neurological imaging and assessment. A positive association was noted between cumulative systemic abnormalities and cumulative ocular abnormalities $(\mathrm{p}=0.001)$. This suggests imploring a comprehensive ophthalmic evaluation in patients with systemic manifestations.

There are a few limitations to the present study. PL with other fatal malformations was excluded from this study. Such exclusion may have drawn a cohort of less affected subjects. The main potential for bias comes from the normal inference of unspecified ocular features. This may produce an understated prevalence of anomalies.

\section{CONCLUSION}

The results recommend an adequate ophthalmic evaluation while screening for a congenital deformity in cases of PL. Addressing PL in clinical practice needs a more comprehensive and multidisciplinary approach.

Contributors All authors included in the paper fulfil the criteria for authorship. AB conceptualised and supervised the study. ESS and PHS designed the computational framework and implementation. ESS wrote the manuscript with input from AS. BS performed the statistical data analysis. All authors discussed the results, provided critical feedback and structured the research, analysis and manuscript.

Funding The authors have not declared a specific grant for this research from any funding agency in the public, commercial or not-for-profit sectors.

Competing interests None declared.

Patient consent for publication Obtained.

Ethics approval The study in question was not submitted to local ethical committee for approval since it involved a retrospective chart review of patients from existing literature and qualifies for exempt status under human subject regulations in our opinion. The study was conducted in accordance with Helsinki Declaration. However for the representative case photograph shown in this article, due informed consent has been obtained and submitted.

Provenance and peer review Not commissioned; externally peer reviewed.

Supplemental material This content has been supplied by the author(s). It has not been vetted by BMJ Publishing Group Limited (BMJ) and may not have been peer-reviewed. Any opinions or recommendations discussed are solely those 
of the author(s) and are not endorsed by BMJ. BMJ disclaims all liability and responsibility arising from any reliance placed on the content. Where the content includes any translated material, BMJ does not warrant the accuracy and reliability of the translations (including but not limited to local regulations, clinical guidelines, terminology, drug names and drug dosages), and is not responsible for any error and/or omissions arising from translation and adaptation or otherwise.

Open access This is an open access article distributed in accordance with the Creative Commons Attribution Non Commercial (CC BY-NC 4.0) license, which permits others to distribute, remix, adapt, build upon this work non-commercially, and license their derivative works on different terms, provided the original work is properly cited, appropriate credit is given, any changes made indicated, and the use is non-commercial. See: http://creativecommons.org/licenses/by-nc/4.0/.

ORCID iDs

Ekta Singh Sahu http://orcid.org/0000-0002-9639-6622

Pavan Humesh Shroff http://orcid.org/0000-0001-8044-1217

\section{REFERENCES}

1 Belet N, Belet U, Tekat A, et al. Proboscis lateralis: radiological evaluation. Pediatr Radiol 2002;32:99-101.

2 John Guerrero MD, Martin Cogen MD, David Kelly MD, et al. Clinicopathologic reports, case reports, and small case series. Proboscis lateralis. Arch Ophthalmol 2001;119:1071-80.

3 Rao PB. Proboscis lateralis. J Laryngol Otol 1963;77:1028-31.

4 Khoo BC, Boo-Chai K. The proboscis lateralis--a 14-year follow-up. Plast Reconstr Surg 1985;75:569-77.

5 David LR, Sanger C, Fisher D, et al. Proboscis lateralis: a rare craniofacial anomaly, reconstruction, and long-term evaluation. $J$ Craniofac Surg 2008;19:1107-13.

6 Meeker LH, Aebli R. Cyclopean eye and lateral proboscis with normal one-half face: report of a case. Arch Ophthal 1947:38:159-73.

7 Lelli GJ, Maher EA, Milite JP, et al. Proboscis lateralis. Ophthalmic Plast Reconstr Surg 2008;24:499-501.
8 Pujari A, Bajaj MS, Shabeer B. Proboscis lateralis. Ophthalmic Plast Reconstr Surg 2017;33:e171.

9 Kolluru V, Coumary S. Proboscis lateralis : a rare bilateral case in association with holoprosencephaly. J Clin Diagn Res 2015;9:QD03-4

10 Arora G, Arora V, Chawla D. Proboscis lateralis-like appendage: description of a new facial anomaly. Ann Plast Surg 2011;66:357-9.

11 Kaufmann-Friedman K, Suprun $\mathrm{H}$. Unusual congenital anomaly, proboscis-like structure arising from mandible. Br J Plast Surg 1971;24:247-9.

12 Fischer H, Eppstein RJ, von Gregory HF, et al. Nasal reconstruction in heminasal deficiency (proboscis lateralis): two case reports, with airway reconstruction in one case. Facial Plast Surg 2014;30:365-70.

13 Antoniades K, Baraister M. Proboscis lateralis: a case report. Teratology 1989;40:193-7.

14 Rontal M, Duritz G. Probocis lateralis: case report and embryologic analysis. Laryngoscope 1977;87:996-1006.

15 Poed LB, Hochhauser L, Bryke C, et al. Proboscis lateralis with associated orbital cyst: detailed Mr and CT imaging and correlative embryopathy. AJNR Am J Neuroradiol 1992;13:1471-6.

16 Nakamura K, Onizuka T. A case of supernumerary Nostril. Plast Reconstr Surg 1987;80:436-41.

17 English GM. Congenital anomalies of the nose, nasopharynx, and paranasal sinuses. In: Otolaryngology. . Lippincott Williams \& Wilkins, 1998: 2. 1-39.

18 Smith HB, Verity DH, Collin JRO. The incidence, embryology, and oculofacial abnormalities associated with eyelid colobomas. Eye 2015;29:492-8.

19 Nakamura KM, Diehl NN, Mohney BG. Incidence, ocular findings, and systemic associations of ocular coloboma: a population-based study. Arch Ophthalmol 2011:129:69-74.

20 Sakamoto Y, Miyamoto J, Nakajima H, et al. New classification scheme of proboscis lateralis based on a review of 50 cases. Cleft Palate Craniofac J 2012;49:201-7.

21 Biber JJ. Proboscic lateralis, a rare malformation of the nose; its genesis and treatment. J Laryngol Otol 1949;63:734-41.

22 Guion-Almeida ML, Zechi-Ceide RM, Richieri-Costa A. Cerebrooculo-nasal syndrome: 13 new Brazilian cases. Am J Med Genet A 2007;143A:3252-66 